\title{
The Heat Shock Response: Systems Biology of Proteotoxic Stress in Aging and Disease
}

\author{
RICHARD I. MORIMOTO \\ Department of Molecular Biosciences, Rice Institute for Biomedical Research, \\ Northwestern University, Evanston, Illinois 60208 \\ Correspondence: r-morimoto@northwestern.edu
}

\begin{abstract}
All organisms sense and respond to environmental and physiological stress by inducing cell stress responses that protect core biosynthetic processes such as DNA repair, protein folding, and clearance of damaged proteins. Of these, the heat shock response (HSR) protects the proteome against acute exposure to elevated temperatures, oxidants, and heavy metals, for example, and to the chronic expression of metastable, aggregation-prone proteins associated with aging and diseases of protein conformation. Induction of the HSR leads to the rapid and robust expression of molecular chaperones and other cell-protective pathways to protect nascent chain synthesis and folding, to prevent misfolding and aggregation, and to promote recovery from stress-induced damage. This review examines the properties of the stress-responsive transcription factor, HSF1 , in the regulation of the HSR, our current understanding of the stress-sensing mechanisms that recognize and distinguish between acute stress such as heat shock and chronic proteostasis imbalance as occurs in neurodegenerative diseases, and the cell nonautonomous control of the HSR by neuronal signaling in metazoans. This complex, systems-wide interdependence ensures cellular health span and organismal life span.
\end{abstract}

The heat-shock response (HSR) is an ancient and highly conserved molecular response to disruptions of protein homeostasis (proteostasis) (Morimoto 2008, 2011; Åkerfelt et al. 2010). The efficient functioning of the proteome is fundamental to all cellular processes and central to organismal health and life span. The stability of each protein within the proteome of every cell and tissue is achieved through interactions with components of the proteostasis network $(\mathrm{PN})$, including molecular chaperones that influence folding, conformation, and stability, and the ubiquitin-dependent proteasome and autophagic activities to clear damaged proteins (Balch et al. 2008; Powers et al. 2009). Among the key stress sensors of the cell are the HSR and the organellar unfolded protein response (UPR) that together orchestrate the health of the proteome (Ron and Walter 2007; Morimoto 2008; Åkerfelt et al. 2010).

Proteostasis, the cellular process that governs the "life of proteins," is organized by the PN, a dynamic network that monitors the functional state of every protein (Balch et al. 2008; Powers et al. 2009; Gidalevitz et al. 2010). The PN responds to an imbalance of misfolded and damaged proteins within each subcellular compartment. Stress and mutations that affect the folding and stability of proteins challenges the PN (Gidalevitz et al. 2006, 2010). Over time and during aging, as protein damage accumulates, these events contribute to proteostatic collapse as occurs in diseases of protein conformation, including neurodegenerative diseases, cancer, and metabolic diseases (Fig. 1). The HSR, by regulating the expression of molecular chaperones and other components of the PN, senses this challenge to proteome stability and resets the $\mathrm{PN}$ to restore the cell and to prevent further protein damage (Fig. 2) (Ananthan et al. 1986; Morimoto 2008; Åkerfelt et al. 2010). Activation of the HSR, therefore, has broad capabilities to protect the cell, not only against subsequent exposures to the same stress signal but also against other stress conditions. This cross-protection to cell stress is also known as hormesis and is supported by evidence that the HSR is cross-protective not only against severe exposures to the same stress condition, but also against exposures to many other types of environmental or chemical stress. Studies on the HSR have established a valuable survival strategy for biological systems, that "a little stress is good." Moreover, because environmental stress is a prominent form of evolutionary pressure, we suggest that a robust HSR is essential for all organisms to survive a stress that cannot be predicted, but for which the organism must be prepared.

Differences among tissues in the composition and properties of the PN could therefore be the basis for distinct molecular responses and tissue-specific proteotoxicity. Neurons as a cell type and the brain seem maladapted for chronic proteotoxic stress, as occurs in Alzheimer disease, Parkinson disease, Huntington disease, and amyotrophic lateral sclerosis (ALS). This has led to speculations that the sensitivity of neurons to protein aggregation is a characteristic of postmitotic cells and is associated with a compromised HSR. Despite the abundance and capacity of chaperones and other components of the PN to maintain folding equilibrium, protein conformational diseases are widespread across multiple tissues, as exemplified by type II diabetes, multiple myeloma, and cystic fibrosis (Morimoto et al. 2011). Chaperones represent a 


\section{ENVIRONMENTAL STRESS PATHOPHYSIOLOGY}

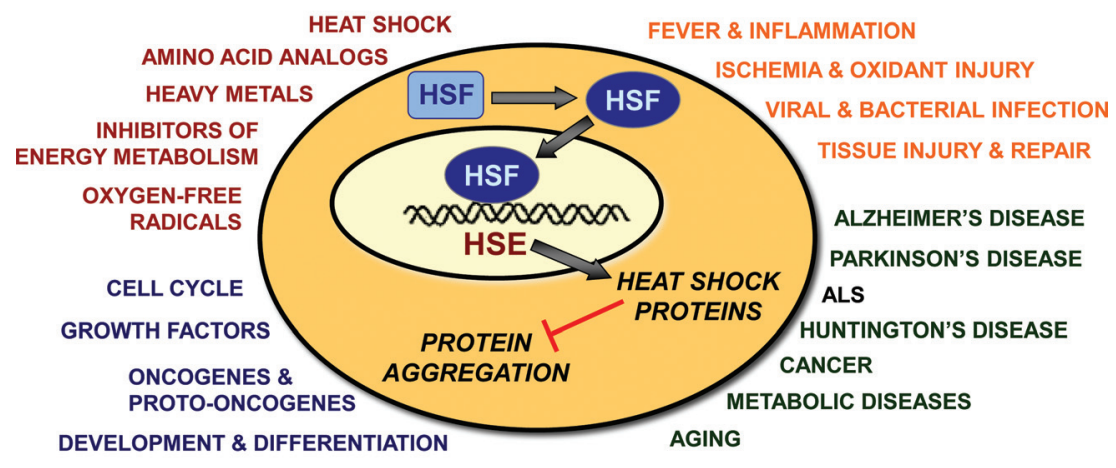

GROWTH \& DEVELOPMENT

\section{PROTEIN CONFORMATIONAL DISEASES}

Figure 1. Cell stress conditions that induce the heat shock response. Major categories of environmental and physiological stress inducers of the HSR include environmental stress, growth and development, pathophysiology, and protein conformational diseases.

significant fraction of the cellular machinery and are expressed in all subcellular compartments to guide folding and prevent misfolding (Bukau et al. 2006; Ron and Walter 2007). Whereas there is substantial understanding of the in vitro biochemical properties of chaperones, much less information is available on chaperone interactions with client substrates in vivo and on the fraction of chaperones that are functionally engaged with client substrates under different normal and stress conditions. One view is that chaperones as catalysts have excess folding capacity and, therefore, a fraction of the total cellular concentrates is available to buffer against unexpected folding requirements. This position requires that cells would maintain a reserve of chaperones for such emergencies. The counterview is that cells have little excess chaperone capacity and that the concentration of chaperones is titrated closely, if not precisely, to the immediate cellular folding requirements. Such precise titration, however, would also imply that the folding environment in the cell is delicate with little capacity for flux in non-native species. One distinct advantage of this latter model, however, is that the HSR would be under precise regulatory control to adjust the PN rapidly and precisely to specific needs. For this to be compatible with the complex and varying cellular environment, the delicate nature of protein homeostasis would need to be paired with a highly robust stress response that responds rapidly to any flux in protein biogenesis.

In recognition of these intrinsic proteostatic requirements, the HSR and HSF-1 function to integrate multiple classes of physiological and environmental stress conditions (Fig. 1) that include (1) environmental stress, such as heat shock, oxidative stress, toxic chemicals, heavy metals, amino acid analogs, and various small-molecule pharmacologically active substances; (2) growth and development, including the cell cycle, growth factors, differentiation, and activation by viral and cellular oncogenes; (3) pathophysiology, such as neuroendocrine stress, tissue injury and repair, fever, inflammation, infection, ischemia, and reperfusion; and (4) protein conformational diseases, including Alzheimer disease, Parkinson disease, ALS, Huntington disease, metabolic diseases, cancer, and aging. These categories are not absolute but provide useful structure to our understanding of the

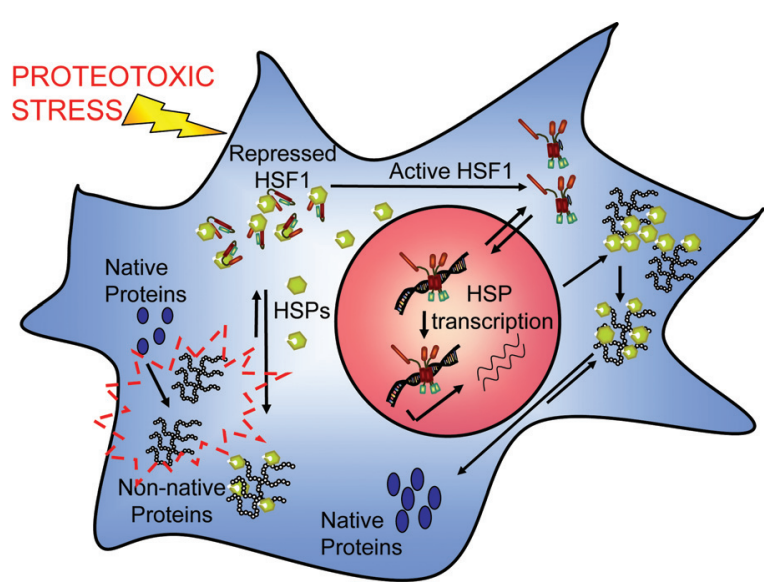

Figure 2. Activation of HSF-1 and expression of chaperones. The HSF-1 cycle can be initiated by a proteotoxic stress signal (i.e., heat shock, HS) that converts the repressed HSF-1 state, weakly associated with molecular chaperones, to the active HSF-1 trimeric state that binds to the heat shock elements (HSEs) in the promoters of HS genes, resulting in their elevated transcription. The shift in equilibrium from repressed to active HSF-1 involves the stress-induced expression of non-native proteins that bind to chaperones, leading to derepression of HSF-1. Induction of the HSR results in high levels of chaperones that bind to nascent chains and other metastable proteins, thus preventing misfolding and aggregation. During attenuation and recovery from stress, the pool of non-native proteins dissipates and homeostasis is restored. 
underlying biology of the HSR and its relevance to diseases of protein conformation.

\section{STRESS-INDUCIBLE REGULATION OF CHAPERONE NETWORKS}

Heat shock genes are ubiquitously expressed during growth and development and are stress responsive in most tissues to protect against proteotoxic stress (Morimoto 1998, 2008; Åkerfelt et al. 2010; Morimoto et al. 2011). Upon exposure of cells and animals to HS, the HSR is induced nearly instantaneously, with the expression of HS genes at higher levels proportional to the intensity, duration, and type of stress (Abravaya et al. 1991; Gasch et al. 2000). Whereas the primary form of regulation is transcriptional, the HSR also involves posttranscriptional control of mRNA stability (Theodorakis and Morimoto 1987) and translational control by the selective expression of HS mRNAs (Banerji et al. 1984).

The transcription of HS genes is regulated by a family of conserved heat shock transcription factors (HSFs). HSF-1 is conserved in humans, Drosophila, Caenorhabditis elegans, and yeast, whereas HSF-2, -3, and -4 are expressed in vertebrates and exhibit diverse functional properties during development, stress, and life span (Sistonen et al. 1992; Wu 1995; McMillan et al. 1998; Morimoto 1998, 2008; Bu et al. 2002; Kallio et al. 2002; Fujimoto et al. 2004; Ảkerfelt et al. 2010). Activation of HSF-1 is induced by acute and chronic stress signals, perturbations of physiology, and signals that affect life span and cause disease (Fig. 1) and are regulated by a multistep process initiated by the conversion of the inert monomeric HSF-1 to nuclear-localized HSF-1 homotrimers, followed by binding to heat shock elements (HSEs) upstream of HS genes, leading to elevated transcription of HS genes (Fig. 2). The events associated with attenuation of the HSR involve transcriptional silencing of DNA-bound HSF-1, release of HSF-1 trimers from the HSE, dephosphorylation of HSF-1, and conversion of trimers back to the inert monomer (Williams and Morimoto 1990; Wu 1995; Morimoto 1998; Åkerfelt et al. 2010). Maintenance of HSF-1 in the control state involves weak and transient interactions with the chaperones Hsp90, Hsp70, and Hsp40 (Abravaya et al. 1992; Shi et al. 1998; Zou et al. 1998). This chaperone-HSF-1 equilibrium is presumably disrupted by the rapid appearance of non-native species that abruptly redirects chaperones to sequester these non-native species, thus releasing HSF-1 to self-associate and form trimers.

All HSFs have the same organization and domains structure. Acquisition of HSF-1 binding to HSEs depends on the amino-terminal DNA binding domain (DBD) that contains a helix-turn-helix motif and intermolecular interactions of the hydrophobic heptad repeats (HR-A/B) that form a leucine zipper coiled-coil. The reversible conversion of HSF-1 from monomer to trimer involves the transition from the inert state in which the intramolecular coiled-coil formed by the amino-terminal HR-A/B interacts with the carboxy-terminal heptad (HR-C) to the functional state comprising solely intermolecular HR-
A/B interactions (Sorger and Nelson 1989). Located at the extreme carboxyl terminus of HSF-1 is the bipartite transcription activation domain (AD1 and AD2), which under control conditions is suppressed by the negative regulatory domain $(\mathrm{RD})$ located between $\mathrm{HR}-\mathrm{A} / \mathrm{B}$ and HR-C.HSF-1 activation is extensively posttranslated modified at serine and threonine residues (Sorger and Pelham 1988; Knauf et al. 1996; Kline and Morimoto 1997; Holmberg et al. 2001; Guettouche et al. 2005), by sumoylation (Hietakangas et al. 2003; Anckar et al. 2006) and by acetylation (Westerheide et al. 2009). Constitutive phosphorylation of HSF-1, for example, at residues S303, S307, and S308, has effects on the negative regulation HSF1, whereas stress-inducible phosphorylation at S230, S326, and S419 is associated with transcriptional activity (Holmberg et al. 2001; Ảkerfelt et al. 2010). The regulation of HSF-1 by posttranslational modifications gives a way to provide precise and tight control of the HSR rather than for HSF-1 to be regulated by a simple on-off switch.

Attenuation of the HSR regulates the transcriptional activity of DNA-bound HSF-1 and its release from the promoters of HS genes. This represents a key step that determines both the duration and level of the HSR. HSF-1 transcriptional activity is negatively regulated by feedback from the elevated levels of the chaperones Hsp90 and Hsp70 through direct interactions with the carboxyterminal activation domain of HSF-1 (Abravaya et al. 1992; Shi et al. 1998). This ensures that the level of chaperone expression achieved is proportional to the stress signal and the levels of non-native substrates. Likewise, the sumoylation of HSF-1 on lysine 298 depends on phosphorylation on serines 303 and 307 and has an inhibitory effect on the HSR. The release of HSF-1 trimers from DNA corresponds to a key step in the attenuation of the HSR and is associated with stress-inducible acetylation at residue $\mathrm{K} 80$ in the HSF-1 DBD to prevent binding to DNA. The inhibitory effect of HSF-1 acetylation is countered by deacetylation by the nicotinamide adenine dinucleotide (NAD)-dependent sirtuin, SIRT1, thus providing a way to control the duration of HSF-1 binding to promoters of HS genes. Intracellular NAD levels are determined by energy homeostasis, and thus the nutritional state of the cell has a direct effect on the regulation of the HSR (Westerheide et al. 2009). Thus, the HSR involves a multistep pathway with both positive and negative regulators in which the chaperones and the posttranslational modifications exert synergistic and opposing regulatory roles to maintain HSF-1 in multiple alternate states of repression and activation and thus control transcriptional activity and attenuation of DNA binding. The combination of these interactions provides HSF1 with the opportunity to exist in multiple states, primed for activation, with a range of control and feedback loops to precisely regulate chaperone levels in the cell.

The underlying mechanisms for transcription at HS gene chromosomal loci have been definitively studied in Drosophila at Hsp70 gene loci at chomosomal loci 87A and $87 \mathrm{C}$, where HSF-1 binding to DNA results in the release of the preinitiated and paused RNA 
polymerase II, which together with the recruitment of P-TEFb, a cyclin-dependent kinase, and other elongation factors results in formation of a stress-regulated RNA Pol II complex that results in the high-level stress-induced transcription of HS messenger RNAs (mRNAs) (Lis et al. 2000; Boehm et al. 2003; Saunders et al. 2003; Ni et al. 2004). Primate cells also exhibit another layer of HSF-1 regulation that involves the spatial relocalization of HSF-1 trimers to heterochromatic satellite III repeats located at chromosome $9 \mathrm{q} 11-\mathrm{q} 12$ to form nuclear stress bodies (Cotto et al. 1997; Jolly et al. 1997, 2002). Located within these satellite III repetitive sequences are thousands of copies of degenerate HSEs to which HSF-1 binds upon heat shock together with RNA polymerase II, acetylated histones, and RNA processing factors, to actively transcribe these sequences (Akkerfelt et al. 2010). The function of these repetitive satellite transcripts and their association with the HSR, however, remain unknown. Recent genome-wide mRNA array studies using yeast and mammalian cells have shown that approximately $3 \%$ of the total genomic loci in yeast are occupied by HSF-1 upon heat shock and that many genes besides chaperones are induced by HS, including genes involved in protein degradation, transport, signal transduction, cytoskeletal maintenance, and metabolism (Gasch et al. 2000; Hahn et al. 2004; Trinklein et al. 2004).

The HSR has often been described as a universal stress response, yet there are specific situations in which the HSR is either not induced or selectively induced. Some examples include early development and exposure of intact organisms to whole body stress (Bienz 1984). Of particular interest are studies on the HSR in the brain and during aging (Sprang and Brown 1987; Blake et al. 1991; Shamovsky and Gershon 2004) that have observed restricted expression of HS in different regions of the brain. Likewise, for neuronal cells in culture, the selective induction of HS genes has been observed; for example, in human neuroblastoma Y79 cells, HSF-1 is activated yet transcription of the Hsp90 but not Hsp70 gene is observed (Mathur et al. 1994). In primary hippocampal neurons from neonatal rat embryos, only HSF-2 but not HSF-1 is expressed; consequently, hippocampal neurons are deficient for the HSR, whereas cocultured astrocytes exhibit a robust HSR (Marcuccilli et al. 1996). Similar observations in primary rodent motor neurons suggest incomplete activation of HSF-1 and a deficient HSR (Batulan et al. 2003).

An additional level of complexity that was revealed from organismal studies on the HSR in C. elegans has shown that the AFD thermosensory neurons regulate the induction of the HSR throughout the animal (Prahlad et al. 2008). Mutations affecting only these neurons inhibited HS-dependent induction of heat shock proteins (HSPs), not only in tissues directly innervated by the AFD neurons but also in other tissues that are not directly innervated by these neurons, such as the intestine and spermatheca. These results suggest that the regulation of cell nonautonomous regulation of HSR by sensory neurons in C. elegans is mediated by signaling through neuroendocrine pathways. AFD-deficient animals lacking the HSR, however, can still respond to chronic protein damage by HSF-1 - dependent expression of chaperones and suppression of protein aggregation (Prahlad and Morimoto 2011). These results suggest that neuronal signaling in C. elegans allows a coordinated response to acute heat shock to ensure a balanced HSR. Down-regulation of the AFD neuronal signal, however, is necessary when aggregation-prone proteins are expressed in a specific tissue to mount an HSF-1-dependent HSR and suppression of aggregation.

\section{PROTEOTOXIC STRESS IN AGING AND DISEASE}

Protein aggregation and the collateral damage associated with the stress of misfolded proteins is a fundamental problem in the biology of aging and human disease. This posits a question as to why the HSR and other stress responses, that are so essential and effective to protect cells against acute stress, are less effective in protecting tissues in diseases of protein conformation. Presumably, this is not just a matter of chronic expression of damaged proteins, because the biological noise emanating from intrinsic error in protein biosynthesis, genetic mutations, and polymorphisms is not insignificant (Fig. 3) (Foss et al. 2007; Drummond and Wilke 2008). The accumulation of aggregates during aging and the age-associated disruption in proteostasis lead to an amplification of protein damage that contributes to cellular toxicity (Fig. 3) (Stadtman 1992; Bence et al. 2001; Morley et al. 2002; Hsu et al. 2003; Walker and Lithgow 2003; Holmberg et al. 2004; Venkatraman et al. 2004; Cohen et al. 2006).

The relationship between life span and protein damage is provocative and supported by evidence that life span regulation by the insulin-like signaling (ILS) pathway and insulin growth factor 1 receptor (IGF1R) depends on HSF1 (Hsu et al. 2003; Morley and Morimoto 2004). A genetic

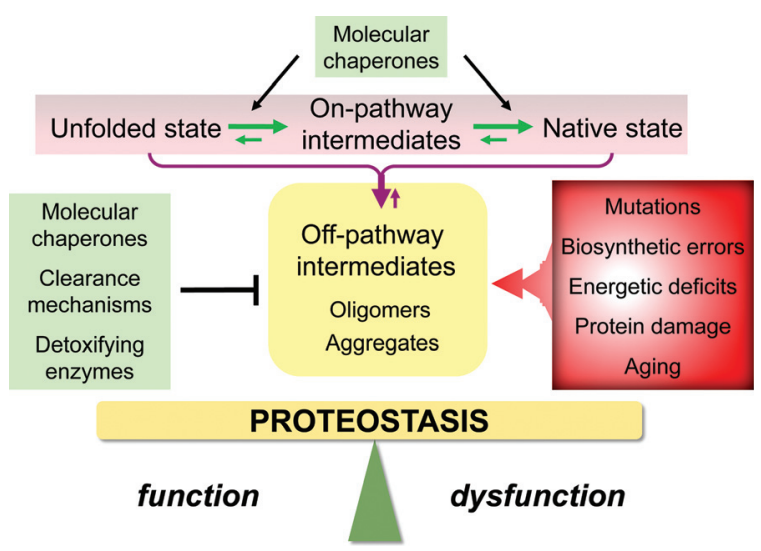

Figure 3. Proteostasis and proteome stability. Proteostasis represents the balance between a functional and dysfunctional cellular state and depends on productive protein folding. Folding intermediates can be on-pathway or off-pathway and form oligomers and aggregates. Suppression of off-pathway intermediates by chaperones and clearance machines is also challenged by protein damage, including mutations, biosynthetic errors, and energetic deficits. 
knockdown of HSF-1 increases aggregation and leads to premature aging, in addition to suppressing life spanenhancing pathways. HSF-1 activity, in response to heat shock, declines precipitously in early adulthood of C. elegans and is associated with the loss of function of proteins with metastable temperature-sensitive (TS) phenotypes (Ben-Zvi et al. 2009). Consistent with these observations, life span-enhancing mutations in the ILS pathway suppress aggregation and cellular dysfunction in $C$. elegans models of $\mathrm{A} \beta$, polyQ, and ataxin-3 (Morley et al. 2002; Cohen et al. 2006; Teixeira-Castro et al. 2011).

Another line of support to link HSF-1 activity with cellular pathways implicated in metabolism and life span is the role of the NAD-dependent sirtruin, SiRT1, in the regulation of the HSR (Westerheide etal.2009). SiRT1 deacetylation in the DNA binding domain of HSF-1 maintains the DNA binding-competent state and thus keeps HSF-1 bound to the HSE. Regulatory override can be achieved by enhancing HSF-1 by altering the levels of NAD, therefore prolonging the "youthfulness" of the proteostatic machineries to ensure that the regulation of proteostasis remains robust.

The relationship between proteostasis decline and aging is a striking feature of protein conformational diseases (Fig. 1). For neurodegenerative diseases, the age at which neurological symptoms appear varies, with Alzheimer disease and Parkinson disease being late onset, Huntington disease showing symptoms during mid to late life, and ALS occurring in early to mid-life. For each of these, as with other conformational diseases, a striking characteristic is that the associated mutant protein shares no similarity in primary sequence, activity, or function but does share common biophysical features of conformational instability and aggregation (Chiti and Dobson 2006). The transition from soluble to aggregated states is exemplified by the triplet-repeat (CAG) diseases of proteins with expanded polyQ proteins that result in Huntington disease, spinocerebellar ataxias, and Kennedy disease (Perutz 1999; Zoghbi and Orr 2000; Ross 2002). In C. elegans and Drosophila models, the expression of polyQ repeats of different lengths in neurons, intestine, and muscle cells has revealed a clear relationship among polyQ length, aggregation, and toxicity (Takeyama et al. 1997; Warrick et al. 1998; Faber et al. 1999; Marsh et al. 2000; Satyal et al. 2000; Parker et al. 2001; Morley et al. 2002; TeixeiraCastro et al. 2011). In young adult animals expressing polyQ in body wall muscle cells and neurons, $<$ Q35 is diffuse and soluble, whereas $>$ Q40 forms insoluble aggregates (Satyal et al. 2000; Morley et al. 2002; Brignull et al. 2006). The appearance of polyQ aggregates in neurons and muscle cells is associated with toxicity that can be suppressed by down-regulation of the ILS pathway, activation of HSF-1, and elevated expression of chaperones and other components of the proteostasis machineries (Morley et al. 2002; Brignull et al. 2006; TeixeiraCastro et al. 2011).

The aggregation and toxicity phenotypes of polyQ in C. elegans have been invaluable in probing the genetics of proteostasis. Genome-wide RNAi screens of C. elegans expressing Q35-YFP have identified approximately 340 genetic modifiers that either enhance or inhibit the PN and thus increase or decrease polyQ aggregation (Nollen et al. 2004; Silva et al. 2011). These modifiers cluster into five major pathways encoding genes involved in RNA metabolism, protein synthesis, protein folding, protein trafficking, and protein degradation. Down-regulation of the RNA-processing machinery, by RNAi, accelerates polyQ aggregation, perhaps owing to an increased burden or imbalance of abnormal proteins. Likewise, enhancing cholinergic signaling at the neuromuscular junction induces the $\mathrm{Ca}^{2+}$-dependent activation of HSF-1 and expression of cytoplasmic chaperones (MC Silva, MD Amaral, and RI Morimoto, unpubl.). This results in a reprogramming of body wall muscle cells by neuronal signaling to obtain an enhanced state of proteostasis that can suppress polyQ aggregation and maintain TS proteins in a soluble and functional state. What appears to be important is to achieve a precise balance of neuronal signaling; the complete loss of the inhibitory GABAergic signal at the neuromuscular junction results in hyperstimulation of muscle cells and enhanced aggregation (Garcia et al. 2007). Together, these results reveal that protein homeostasis strongly depends on cell nonautonomous regulation by the nervous system.

We propose that the susceptibility of the cellular proteostasis environment to conformational disease is a direct consequence of multiple events initiated by agedependent changes in the PN and amplified by cumulative protein damage (Fig. 4). In addition to the decline of the HSR and UPR in early adulthood in C. elegans, the expression of disease-associated aggregation-prone proteins has global consequences on the overall stability of the proteome, for example, metastable proteins harboring missense mutations that result in TS phenotypes becoming targets for aggregation when coexpressed with expanded polyQ proteins or mutant SOD1 in neurons and muscle cells (Gidalevitz et al. 2006, 2009, 2010). This reveals that the proteome expressed in these tissues does not have additional capacity for non-native states and that the PN is delicately balanced with little additional capacity (Fig. 4). The age-associated decline in the PN is probably due to a compromise in the robustness of cell stress responses and a reduced capacity of chaperones and clearance machines (Stadtman 1992; Shamovsky and Gershon 2004; Ben-Zvi et al. 2009).

\section{PROTEOSTASIS THERAPEUTICS AND THE REGULATION OF HSF-1 BY SMALL MOLECULES}

Regulation of the HSR by small molecules not only provides chemical genetic tools for the analysis of the HSR but also establishes a therapeutic strategy to enhance the cellular proteostasis environment to prevent misfolding of diverse disease-associated proteins (Westerheide and Morimoto 2005; Calamini et al. 2011). This strategy targeted at the PN and the cellular environment is an alternative to correcting folding instability by small-molecule pharmacological chaperones. Compounds with diverse activities that enhance the $\mathrm{PN}$ include protease 


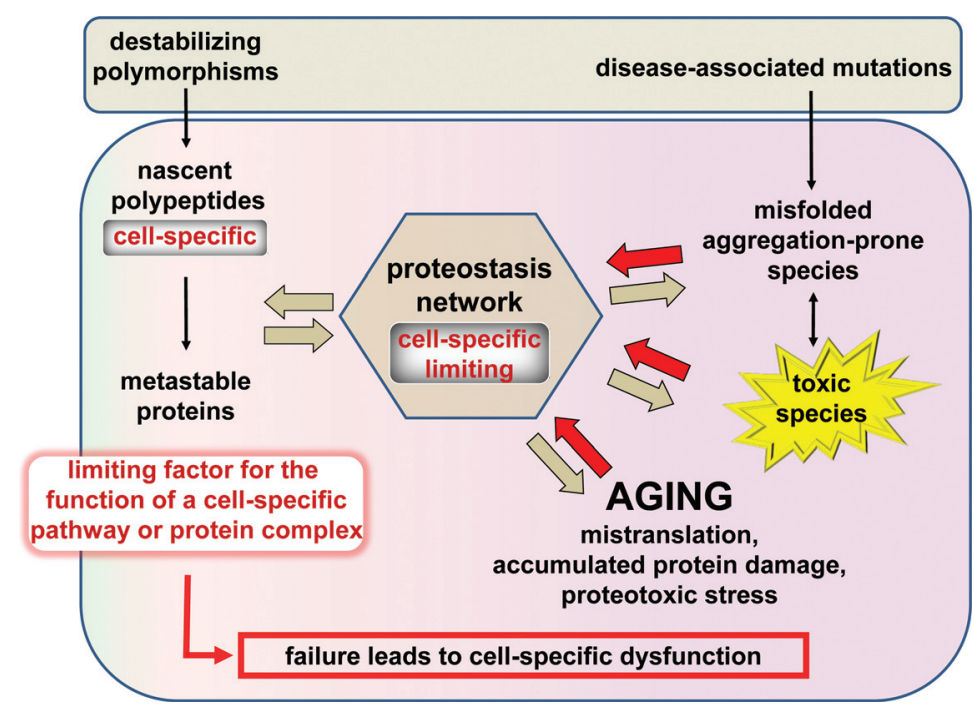

Figure 4. The proteostasis challenge in stress, aging, and disease. When challenged by aggregation-prone proteins associated with protein conformational diseases, the proteostasis network $(\mathrm{PN})$ becomes imbalanced as chaperones and clearance machineries are overwhelmed by non-native proteins, leading to misfolding and the appearance of oligomeric toxic species. The effects of aging amplify protein damage, leading to an irreversible decline in the PN. The global collapse in the PN can also explain cell-specific dysfunction as polymorphisms become metastable and result in both loss-of-function and gain-of-function aggregation.

inhibitors (DCIC, TPCK, and TLCK) and proteasome inhibitors (MG132 and lactacystin) that induce the HSR by increasing the pool of non-native proteins targeted to the proteasome (Mathew et al. 1998; Rossi et al. 1998), and the Hsp90 inhibitors (radicicol, geldanamycin, and 17AAG), which activate the HSR by derepression of the HSR 1 (Zou et al. 1998; Bagatell et al. 2000; Whitesell et al. 2003; Whitesell and Lindquist 2005). Other pharmacologically active small molecules that induce the HSR include the nonsteroidal anti-inflammatory drug (NSAID), sodium salicylate, which activates HSF1 DNA binding and synergizes with other stress conditions to induce a complete HSR (Jurivich et al. 1992). Other molecules associated with inflammation, including the widely used NSAID indomethacin and inflammatory modulators such as arachidonic acid and the cyclopentenone prostaglandins (PGA1, PGA2, and PGJ2), all induce HSF-1 DNA binding and the HSR (Amici et al. 1992; Jurivich et al. 1994; Lee et al. 1995). Among the more widely used small molecules for induction of the HSR is the triterpenoid celastrol isolated from the Chinese plant Triptergium wilfordii, which induces multiple stress responses including the HSR, UPR, and the anti-oxidant response (Westerheide et al. 2004; Trott et al. 2008).

A recent large-scale (approximately 1 million) smallmolecule screen performed in human tissue culture cells for HSF-1-dependent proteostasis regulators (PRs) identified approximately 300 chemical inducers of the HSR (Calamini et al. 2011). These PRs were classified by their stress response signatures as HSR- and HSF-1-selective, by induction of both HSF-1 and the lumen UPR, and by activation of the HSF-1, UPR, and the antioxidant response (Fig. 5). These properties, activating multiple stress response pathways, were used to complement the

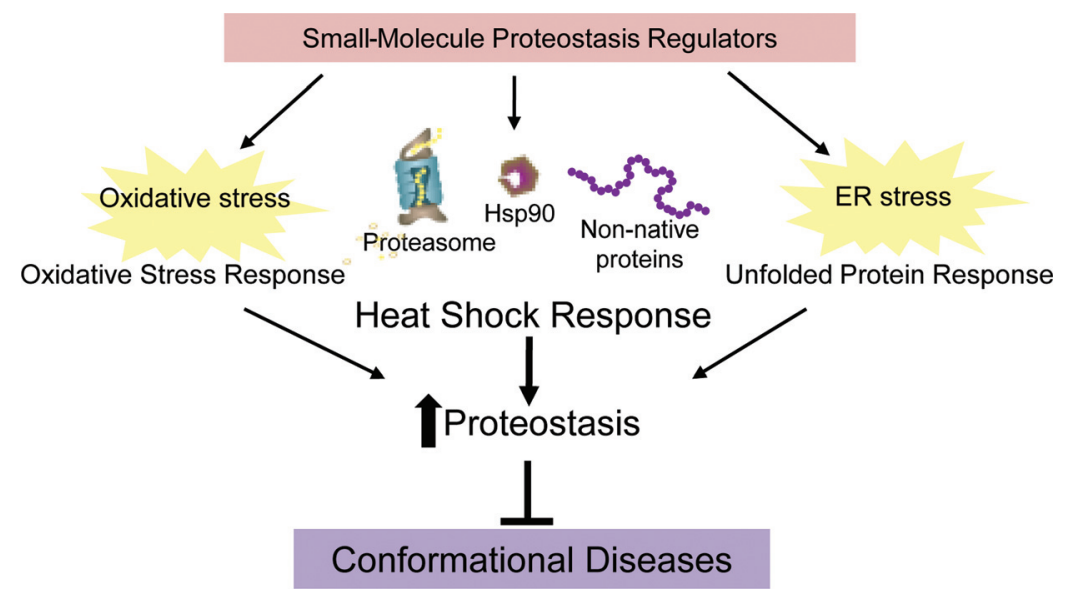

Figure 5. Small-molecule proteostasis regulators restore protein folding in the cell. Proteostasis can be restored in the cell by small molecules that activate cell stress pathways either alone or in various combinations to suppress protein aggregation. 
cell's biological response to specific aggregation-prone proteins and correct the proteostatic deficiency. For example, small-molecule inducers of the HSR that restored the cytoplasmic PN were effective in the suppression of polyQ-mediated proteotoxicity but were insufficient to correct the folding of mutant cystic fibrosis transmembrane regulator (CFTR). Folding of mutant CFTR, however, was enhanced when the UPR was co-induced with the HSR and when the antioxidant response was co-induced with the HSR and UPR. Oxidative stress is associated with the pathogenesis of many diseases including Alzheimer disease, Parkinson disease, ALS, and cystic fibrosis, and thus, activation of the antioxidant response pathway in conjunction with the HSR may have broad beneficial implications. In support of this, PRs that induced multiple stress-protective pathways were highly effective in multiple disease models affecting distinct cellular compartments. This reveals that the redundant and overlapping profiles of PRs, with HSF-1 at the stress network hub, functions in concert with other stress signaling pathways to coordinate the PN. By this approach, the growing knowledge of the PN and stress biology can be used to promote the health of the cell by tuning the efficacy of small-molecule PRs by their stress response signatures to manage the imbalance caused by diverse misfolding-prone proteins. The strategy of PN adjustment by small-molecule PRs provides a previously undeveloped approach to restoring cellular proteostatic capabilities and thus achieving proteome balance in both lossand gain-of-function diseases.

\section{CONCLUSIONS}

The challenge to the cell and organism in the face of acute and chronic proteotoxic stress associated with aging, stress, and disease is a system-wide decline in proteostasis and cellular function. The consequence of proteome mismanagement is substantial as evident by the large and growing number of diseases of protein conformation. Protein aggregation, however, is not an isolated event and, once imbalanced, causes an acceleration in the levels of damaged proteins, leading to a rapid decline in biosynthetic and repair activities and multiple cell stress responses, which over time have deleterious consequences on the health and aging of the organism.

\section{ACKNOWLEDGMENTS}

R.I.M. thanks the National Institutes of Health (National Institute of General Medical Sciences, National Institute on Aging, and National Institute of Neurological Disorders and Stroke), the Human Frontiers Science Program, the Ellison Foundation, and the Daniel F. and Ada L. Rice Foundation for their generous support, and members of the laboratory who contributed to the work described herein.

\section{REFERENCES}

Abravaya K, Phillips B, Morimoto RI. 1991. Attenuation of the heat shock response in HeLa cells is mediated by the release of bound heat shock transcription factor and is modulated by changes in growth and in heat shock temperatures. Genes Dev 5: $2117-2127$.

Abravaya K, Myers MP, Murphy SP, Morimoto RI. 1992. The human heat shock protein hsp70 interacts with HSF, the transcription factor that regulates heat shock gene expression. Genes Dev 6: 1153-1164.

Åkerfelt M, Morimoto RI, Sistonen L. 2010. Heat shock factors: Integrators of cell stress, development, and lifespan. Nat Rev Mol Cell Biol 11: 545-555.

Amici C, Sistonen L, Santoro MG, Morimoto RI. 1992. Antiproliferative prostaglandins activate heat shock transcription factor. Proc Natl Acad Sci 89: 6227-6231.

Ananthan J, Goldberg AL, Voellmy R. 1986. Abnormal proteins serve as eukaryotic stress signals and trigger the activation of heat shock genes. Science 232: 522-524.

Anckar J, Hietakangas V, Denessiouk K, Thiele DJ, Johnson MS, Sistonen L. 2006. Inhibition of DNA binding by differential sumoylation of heat shock factors. Mol Cell Biol 26: 955-964.

Bagatell R, Paine-Murrieta GD, Taylor CW, Pulcini EJ, Akinaga S, Benjamin IJ, Whitesell L. 2000. Induction of a heat shock factor 1-dependent stress response alters the cytotoxic activity of hsp90-binding agents. Clin Cancer Res 6: 3312-3318.

Balch WE, Morimoto RI, Dillin A, Kelly JW. 2008. Adapting proteostasis for disease intervention. Science 319: 916-919.

Banerji SS, Theodorakis NG, Morimoto RI. 1984. Heat shockinduced translational control of HSP70 and globin synthesis in chicken reticulocytes. Mol Cell Biol 4: 2437-2448.

Batulan Z, Shinder GA, Minotti S, He BP, Doroudchi MM, Nalbantoglu J, Strong MJ, Durham HD. 2003. High threshold for induction of the stress response in motor neurons is associated with failure to activate HSF1. J Neurosci 23: 57895798.

Bence NF, Sampat RM, Kopito RR. 2001. Impairment of the ubiquitin-proteasome system by protein aggregation. Science 292: $1552-1555$.

Ben-Zvi A, Miller EA, Morimoto RI. 2009. Collapse of proteostasis represents an early molecular event in Caenorhabditis elegans aging. Proc Natl Acad Sci 106: 14914-14919.

Bienz M. 1984. Developmental control of the heat shock response in Xenopus. Proc Natl Acad Sci 81: 3138-3142.

Blake MJ, Udelsman R, Feulner GJ, Norton DD, Holbrook NJ. 1991. Stress-induced heat shock protein 70 expression in adrenal cortex: An adrenocorticotropic hormone-sensitive, age-dependent response. Proc Natl Acad Sci 88: 9873-9877.

Boehm AK, Saunders A, Werner J, Lis JT. 2003. Transcription factor and polymerase recruitment, modification, and movement on dhsp70 in vivo in the minutes following heat shock. Mol Cell Biol 23: 7628-7637.

Brignull HR, Moore FE, Tang SJ, Morimoto RI. 2006. Polyglutamine proteins at the pathogenic threshold display neuronspecific aggregation in a pan-neuronal Caenorhabditis elegans model. J Neurosci 26: 7597-7606.

Bu L, Jin Y, Shi Y, Chu R, Ban A, Eiberg H, Andres L, Jiang H, Zheng G, Qian M, et al.. 2002. Mutant DNA-binding domain of HSF4 is associated with autosomal dominant lamellar and Marner cataract. Nat Genet 31: 276-278.

Bukau B, Weissman J, Horwich A. 2006. Molecular chaperones and protein quality control. Cell 125: 443-451.

Calamini B, Silva C, Madoux F, Hutt DM, Khanna S, Chalfant M, Saldanha SA, Hodder P, Tait B, Garza D, et al. 2011. Small molecule proteostasis regulators for protein conformational disease. Nat Chem Biol 8: 185-196.

Chiti F, Dobson CM. 2006. Protein misfolding, functional amyloid, and human disease. Annu Rev Biochem 75: $333-$ 366.

Cohen E, Bieschke J, Perciavalle RM, Kelly JW, Dillin A. 2006. Opposing activities protect against age-onset proteotoxicity. Science 313: 1604-1610.

Cotto J, Fox S, Morimoto RI. 1997. HSF1 granules. A novel stress-induced nuclear domain in human cells. J Cell Sci 110: $2925-2934$. 
Drummond DA, Wilke CO. 2008. Mistranslation-induced protein misfolding as a dominant constraint on coding-sequence evolution. Cell 134: 341-352.

Faber PW, Alter JR, MacDonald ME, Hart AC. 1999. Polyglutamine-mediated dysfunction and apoptotic death of a Caenorhabditis elegans sensory neuron. Proc Natl Acad Sci 96: 179-184.

Foss EJ, Radulovic D, Shaffer SA, Ruderfer DM, Bedalov A, Goodlett DR, Kruglyak L. 2007. Genetic basis of proteome variation in yeast. Nat Genet 39: 1369-1375.

Fujimoto M, Izu H, Seki K, Fukuda K, Nishida T, Yamada S, Kato K, Yonemura S, Inouye S, Nakai A. 2004. HSF4 is required for normal cell growth and differentiation during mouse lens development. EMBO J 23: 4297-4306.

Garcia SM, Casanueva MO, Silva MC, Amaral MD, Morimoto RI. 2007. Neuronal signaling modulates protein homeostasis in Caenorhabditis elegans post-synaptic muscle cells. Genes Dev 21: 3006-3016.

Gasch AP, Spellman PT, Kao CM, Carmel-Harel O, Eisen MB, Storz G, Botstein D, Brown PO. 2000. Genomic expression programs in the response of yeast cells to environmental changes. Mol Biol Cell 11: 4241-4257.

Gidalevitz T, Ben-Zvi A, Ho KH, Brignull HR, Morimoto RI. 2006. Progressive disruption of cellular protein folding in models of polyglutamine diseases. Science 311: 1471-1474.

Gidalevitz T, Krupinski T, Garcia S, Morimoto RI. 2009. Destabilizing protein polymorphisms in the genetic background direct phenotypic expression of mutant SOD1 toxicity. PLoS Genet 5: e1000399.

Gidalevitz T, Kikis EA, Morimoto RI. 2010. A cellular perspective on conformational disease: The role of genetic background and proteostasis networks. Curr Opin Struct Biol 20: 23-32.

Guettouche T, Boellmann F, Lane WS, Voellmy R. 2005. Analysis of phosphorylation of human heat shock factor 1 in cells experiencing a stress. BMC Biochem 6: 4.

Hahn JS, Hu Z, Thiele DJ, Iyer VR. 2004. Genome-wide analysis of the biology of stress responses through heat shock transcription factor. Mol Cell Biol 24: 5249-5256.

Hietakangas V, Ahlskog JK, Jakobsson AM, Hellesuo M, Sahlberg NM, Holmberg CI, Mikhailov A, Palvimo JJ, Pirkkala L, Sistonen L. 2003. Phosphorylation of serine 303 is a prerequisite for the stress-inducible SUMO modification of heat shock factor 1. Mol Cell Biol 23: 2953-2968.

Holmberg CI, Hietakangas V, Mikhailov A, Rantanen JO, Kallio M, Meinander A, Hellman J, Morrice N, MacKintosh C, Morimoto RI, et al. 2001. Phosphorylation of serine 230 promotes inducible transcriptional activity of heat shock factor 1 . EMBO J 20: 3800-3810.

Holmberg CI, Staniszewski KE, Mensah KN, Matouschek A, Morimoto RI. 2004. Inefficient degradation of truncated polyglutamine proteins by the proteasome. EMBO J 23: $4307-$ 4318 .

Hsu AL, Murphy CT, Kenyon C. 2003. Regulation of aging and age-related disease by DAF-16 and heat-shock factor. Science 300: $1142-1145$.

Jolly C, Morimoto RI, Michel R-J, Vourc'h C. 1997. HSF1 transcription factor concentrates in nuclear foci during heat shock II. Relationship with transcription sites. J Cell Sci 110: 2935-2942.

Jolly C, Konecny L, Grady DL, Kutskova YA, Cotto JJ, Morimoto RI, Vourc'h C. 2002. In vivo binding of active HSF1 to human chromosome 9 heterochromatin during stress. J Cell Biol 156: $775-781$.

Jurivich DA, Sistonen L, Kroes RA, Morimoto RI. 1992. Effect of sodium salicylate on the human heat shock response. Science 255: 1243-1245.

Jurivich DA, Sistonen L, Sarge KD, Morimoto RI. 1994. Arachidonate is a potent modulator of human heat shock gene transcription. Proc Natl Acad Sci 91: 2280-2284.

Kallio M, Chang Y, Manuel M, Alastalo TP, Rallu M, Gitton Y, Pirkkala L, Loones MT, Paslaru L, Larney S, et al. 2002. Brain abnormalities, defective meiotic chromosome synapsis and female subfertility in HSF2 null mice. EMBO J 21: 25912601.

Kline MP, Morimoto RI. 1997. Repression of the heat shock factor 1 transcriptional activation domain is modulated by constitutive phosphorylation. Mol Cell Biol 17: 21072115.

Knauf U, Newton EM, Kyriakis J, Kingston RE. 1996. Repression of human heat shock factor 1 activity at control temperature by phosphorylation. Genes Dev 10: 2782-2793.

Lee BS, Chen J, Angelidis C, Jurivich DA, Morimoto RI. 1995. Pharmacological modulation of heat shock factor 1 by antiinflammatory drugs results in protection against stress-induced cellular damage. Proc Natl Acad Sci 92: 7207-7211.

Lis JT, Mason P, Peng J, Price DH, Werner J. 2000. P-TEFb kinase recruitment and function at heat shock loci. Genes Dev 14: $792-803$.

Marcuccilli CJ, Mathur SK, Morimoto RI, Miller RJ. 1996. Regulatory differences in the stress response of hippocampal neurons and glial cells after heat shock. J Neurosci 16: $478-$ 485.

Marsh JL, Walker H, Theisen H, Zhu YZ, Fielder T, Purcell J, Thompson LM. 2000. Expanded polyglutamine peptides alone are intrinsically cytotoxic and cause neurodegeneration in Drosophila. Hum Mol Genet 9: 13-25.

Mathew A, Mathur SK, Morimoto RI. 1998. Heat shock response and protein degradation: Regulation of HSF2 by the ubiquitinproteasome pathway. Mol Cell Biol 18: 5091-5098.

Mathur SK, Sistonen L, Brown IR, Murphy SP, Sarge KD, Morimoto RI. 1994. Deficient induction of human hsp70 heat shock gene transcription in Y79 retinoblastoma cells despite activation of heat shock factor 1. Proc Natl Acad Sci 91: 8695-8699.

McMillan DR, Xiao X, Shao L, Graves K, Benjamin IJ. 1998. Targeted disruption of heat shock transcription factor 1 abolishes thermotolerance and protection against heat-inducible apoptosis. J Biol Chem 273: 7523-7528.

Morimoto RI. 1998. Regulation of the heat shock transcriptional response: Cross talk between a family of heat shock factors, molecular chaperones, and negative regulators. Genes Dev 12: $3788-3796$.

Morimoto RI. 2008. Proteotoxic stress and inducible chaperone networks in neurodegenerative disease and aging. Genes Dev 22: $1427-1438$.

Morimoto RI, Selkoe DJ, Kelly JW, eds. 2011. Protein homeostasis. Cold Spring Harbor Laboratory Press, Cold Spring Harbor, NY.

Morley JF, Morimoto RI. 2004. Regulation of longevity in Caenorhabditis elegans by heat shock factor and molecular chaperones. Mol Biol Cell 15: 657-664.

Morley JF, Brignull HR, Weyers JJ, Morimoto RI. 2002. The threshold for polyglutamine-expansion protein aggregation and cellular toxicity is dynamic and influenced by aging in Caenorhabditis elegans. Proc Natl Acad Sci 99: 1041710422.

Ni Z, Schwartz BE, Werner J, Suarez JR, Lis JT. 2004 Coordination of transcription, RNA processing, and surveillance by P-TEFb kinase on heat shock genes. Mol Cell 13: 55-65.

Nollen EA, Garcia SM, van Haaften G, Kim S, Chavez A, Morimoto RI, Plasterk RH. 2004. Genome-wide RNA interference screen identifies previously undescribed regulators of polyglutamine aggregation. Proc Natl Acad Sci 101: 64036408.

Parker JA, Connolly JB, Wellington C, Hayden M, Dausset J, Neri C. 2001. Expanded polyglutamines in Caenorhabditis elegans cause axonal abnormalities and severe dysfunction of PLM mechanosensory neurons without cell death. Proc Natl Acad Sci 98: 13318-13323.

Perutz MF. 1999. Glutamine repeats and neurodegenerative diseases: Molecular aspects. Trends Biochem Sci 24: 5863.

Powers ET, Morimoto RI, Dillin A, Kelly JW, Balch WE. 2009. Biological and chemical approaches to diseases of proteostasis deficiency. Annu Rev Biochem 78: 959-991. 
Prahlad V, Morimoto RI. 2011. Neuronal circuitry regulates the response of C. elegans to misfolded proteins. Proc Natl Acad Sci 108: 14204-14209.

Prahlad V, Cornelius T, Morimoto RI. 2008. Regulation of the cellular heat shock response in Caenorhabditis elegans by thermosensory neurons. Science 320: $811-814$.

Ron D, Walter P. 2007. Signal integration in the endoplasmic reticulum unfolded protein response. Nat Rev Mol Cell Biol 8: $519-529$.

Ross CA. 2002. Polyglutamine pathogenesis: Emergence of unifying mechanisms for Huntington's disease and related disorders. Neuron 35: 819-822.

Rossi A, Elia G, Santoro MG. 1998. Activation of the heat shock factor 1 by serine protease inhibitors. An effect associated with nuclear factor- $\kappa \mathrm{B}$ inhibition. $J$ Biol Chem 273: $16446-$ 16452.

Satyal SH, Schmidt E, Kitagawa K, Sondheimer N, Lindquist S, Kramer JM, Morimoto RI. 2000. Polyglutamine aggregates alter protein folding homeostasis in Caenorhabditis elegans. Proc Natl Acad Sci 97: 5750-5755.

Saunders A, Werner J, Andrulis ED, Nakayama T, Hirose S, Reinberg D, Lis JT. 2003. Tracking FACT and the RNA polymerase II elongation complex through chromatin in vivo. Science 301: 1094-1096.

Shamovsky I, Gershon D. 2004. Novel regulatory factors of HSF1 activation: Facts and perspectives regarding their involvement in the age-associated attenuation of the heat shock response. Mech Ageing Dev 125: 767-775.

Shi Y, Mosser DD, Morimoto RI. 1998. Molecular chaperones as HSF1-specific transcriptional repressors. Genes Dev 12: 654-666.

Silva MC, Fox S, Beam M, Thakkar H, Amaral MD, Morimoto RI. 2011. A genetic screening strategy identifies novel regulators of the proteostasis network. PLOS Gen 12: e1002438. doi: 10.1371 /journal.pgen.1002438.

Sistonen L, Sarge KD, Phillips B, Abravaya K, Morimoto RI. 1992. Activation of heat shock factor 2 during hemin-induced differentiation of human erythroleukemia cells. Mol Cell Biol 12: $4104-4111$.

Sorger PK, Nelson HC. 1989. Trimerization of a yeast transcriptional activator via a coiled-coil motif. Cell 59: 807-813.

Sorger PK, Pelham HR. 1988. Yeast heat shock factor is an essential DNA-binding protein that exhibits temperature-dependent phosphorylation. Cell 54: $855-864$.

Sprang GK, Brown IR. 1987. Selective induction of a heat shock gene in fiber tracts and cerebral neurons of the rabbit brain detected by in situ hybridization. Brain Res 427: 89-93.

Stadtman ER. 1992. Protein oxidation and aging. Science 257: $1220-1224$

Takeyama S, Bimston DN, Matsuzawa S, Freeman BC, AimeSempe C, Xie Z, Morimoto RI, Reed JC. 1997. BAG-1 modulates the chaperone activity of $\mathrm{Hsp} 70 / \mathrm{Hsc} 70$. EMBO J 16: 4887-4896.

Takeyama K, Ito S, Yamamoto A, Tanimoto H, Furutani T, Kanuka H, Miura M, Tabata T, Kato S. 2002. Androgen-dependent neurodegeneration by polyglutamine-expanded human androgen receptor in Drosophila. Neuron 35: 855-864.
Teixeira-Castro A, Ailion M, Jalles A, Brignull HR, Vilaça JL, Dias N, Rodrigues P, Oliveira JF, Neves-Carvalho A, Morimoto RI, et al. 2011. Neuron-specific proteotoxicity of mutant ataxin-3 in C. elegans: Rescue by the DAF-16 and HSF1 pathways. Hum Mol Genet 20: 2996-3009.

Theodorakis NG, Morimoto RI. 1987. Posttranscriptional regulation of hsp70 expression in human cells: Effects of heat shock, inhibition of protein synthesis, and adenovirus infection on translation and mRNA stability. Mol Cell Biol 7: 4357-4368.

Trinklein ND, Murray JI, Hartman SJ, Botstein D, Myers RM. 2004. The role of heat shock transcription factor 1 in the genome-wide regulation of the mammalian heat shock response. Mol Biol Cell 15: 1254-1261.

Trott A, West JD, Klaic L, Westerheide SD, Silverman RB, Morimoto RI, Morano KA. 2008. Activation of heat shock and antioxidant responses by the natural product celastrol: Transcriptional signatures of a thiol-targeted molecule. Mol Biol Cell 19: 1104-1112.

Venkatraman P, Wetzel R, Tanaka M, Nukina N, Goldberg AL. 2004. Eukaryotic proteasomes cannot digest polyglutamine sequences and release them during degradation of polyglutamine-containing proteins. Mol Cell 14: 95-104.

Walker GA, Lithgow GJ. 2003. Lifespan extension in C. elegans by a molecular chaperone dependent upon insulin-like signals. Aging Cell 2: 131-139.

Warrick JM, Paulson HL, Gray-Board GL, Bui QT, Fischbeck KH, Pittman RN, Bonini NM. 1998. Expanded polyglutamine protein forms nuclear inclusions and causes neural degeneration in Drosophila. Cell 93: 939-949.

Westerheide SD, Morimoto RI. 2005. Heat shock response modulators as therapeutic tools for diseases of protein conformation. J Biol Chem 280: 33097-33100.

Westerheide SD, Bosman JD, Mbadugha BN, Kawahara TL, Matsumoto G, Kim S, Gu W, Devlin JP, Silverman RB, Morimoto RI. 2004. Celastrols as inducers of the heat shock response and cytoprotection. J Biol Chem 279: 56053-56060.

Westerheide SD, Anckar J, Stevens S, Sistonen L, Morimoto RI. 2009. Stress-inducible regulation of heat shock factor 1 by the deacetylase SIRT1. Science 323: 1063-1066.

Whitesell L, Lindquist SL. 2005. HSP90 and the chaperoning of cancer. Nat Rev Cancer 5: 761-772.

Whitesell L, Bagatell R, Falsey R. 2003. The stress response: Implications for the clinical development of hsp90 inhibitors. Curr Cancer Drug Targets 3: 349-358.

Williams GT, Morimoto RI. 1990. Maximal stress: Induced transcription of the human HSP70 promoter involves interactions with the basal promoter independent of rotational alignment. Mol Cell Biol 10: 3125-3146.

Wu C. 1995. Heat shock transcription factors: Structure and regulation. Annu Rev Cell Dev Biol 11: 441-469.

Zoghbi HY, Orr HT. 2000. Glutamine repeats and neurodegeneration. Annu Rev Neurosci 23: 217-247.

Zou J, Guo Y, Guettouche T, Smith DF, Voellmy R. 1998. Repression of heat shock transcription factor HSF1 activation by HSP90 (HSP90 complex) that forms a stress-sensitive complex with HSF1. Cell 94: 471-480. 


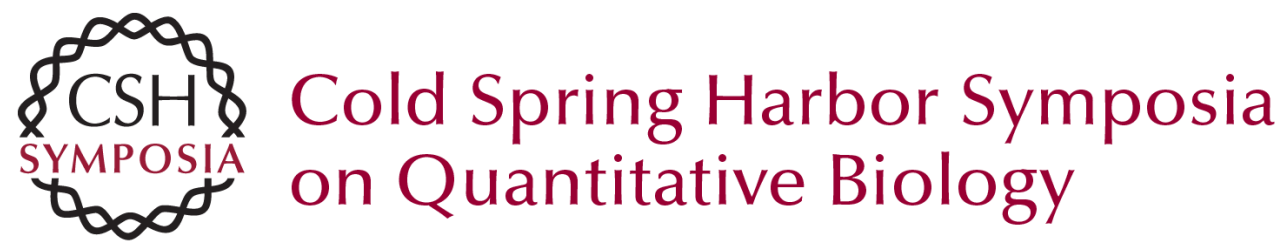

\section{The Heat Shock Response: Systems Biology of Proteotoxic Stress in Aging and Disease}

Richard I. Morimoto

Cold Spring Harb Symp Quant Biol 2011 76: 91-99 originally published online February 27, 2012 Access the most recent version at doi:10.1101/sqb.2012.76.010637

References This article cites 93 articles, 61 of which can be accessed free at: http://symposium.cshlp.org/content/76/91.full.html\#ref-list-1

License

Email Alerting Receive free email alerts when new articles cite this article - sign up in Service the box at the top right corner of the article or click here. 